\title{
Bird and hail stone impact resistance analysis on a jet engine composite air inlet
}

\author{
Radek Doubrava ${ }^{1, *}$, Martin Oberthor ${ }^{1}$, Petr Bělský ${ }^{1}$ and Jan Raška ${ }^{1}$ \\ ${ }^{1}$ VZLÚ - Czech Aerospace Research Centre, Strength of Structure Department, 19905 Prague, \\ Czech Republic
}

\begin{abstract}
Bird or hail stone impacts are an important phenomenon that must be taken into consideration when designing aircraft. As engines are the sole thrust-providing mechanisms of an aircraft, it is critical that the effects of bird or hail stone strikes on engine inlets and systems be investigated and mitigated to the greatest extent possible. A combination of experiments and numerical simulations is necessary to properly understand the behaviour of a bird or hail stone during impact and the reaction of the impacted material with the structure. A simulation methodology is developed and validated to certify the bird or hail stone strike resistance of composite air ducts designed for a new generation of jet training aircraft. Physical impact tests were performed on real composite parts. Numerical simulation results were compared with test results. Numerical simulation was also used for test preparation and optimization of the test rig design from the point of view of the influence of the stiffness of the surrounding aircraft structure. The validated modelling procedure allows the analysis of numerous impact scenarios, improving the optimization procedures for aircraft component design and reducing the cost of development by reducing the need to manufacture test prototypes.
\end{abstract}

\section{Introduction}

Bird or hail stone strikes are an important phenomenon that must be taken into consideration when designing aircraft. Most major bird strike incidents result from engine ingestion [1]. As engines are the sole thrust-providing mechanisms of an aircraft, it is critical that the effects of bird or hail stone strikes on engine inlets and systems be investigated and mitigated to the greatest extent possible. For example, a quieter engine means that birds will have less warning that an aircraft is approaching, and the continual reduction in aircraft engine count enabled by more powerful engines has reduced redundancy. As a result, it is more important than ever to study and understand the mechanics of bird strikes.

An increasing number of aircraft manufacturers, aviation companies, and government authorities have been conducting advanced research and development programmes in an effort to reduce the annual cost, the number of injuries, and the fatalities that result from the

\footnotetext{
*Corresponding author: doubrava@vzlu.cz
} 
collision of aircraft with wildlife [2]. To eliminate the harmful effects of bird or hail stone strikes, two main approaches are typically implemented:

1. Bird or hail stone strike prevention strategies that attempt to reduce the probability of a bird or hail stone strike incident occurring.

2. Aircraft certification programmes that employ various measures to maintain the integrity of an aircraft against the high loads resulting from high velocity impacts in accordance with international certification standards.

The second approach will be further developed in this study. International certification regulations require that all forward-facing aircraft components be proven to withstand bird or hail stone strikes to a certain level before they can be used in an aircraft [2]. A bird or hail stone impact test provides a direct method for determining bird strike resistance; however, the design of aircraft structures typically involves many iterations, from design to manufacturing to testing and back, requiring that many bird impact tests be conducted. This is not only time consuming but also costly. Furthermore, experimental data from these tests are often narrowly focused, constituting a barrier for their direct use in refining structural design. Owing to these shortcomings, several numerical methods have been developed to simulate bird or hail stone strikes to reduce the number of intermediate tests required and subsequently shorten the duration of the component design phase [3, 4].

The approach for the development of a composite air inlet for a new generation of jet training aircraft from the point of view of high-speed impact resistance is shown in Figure 1.

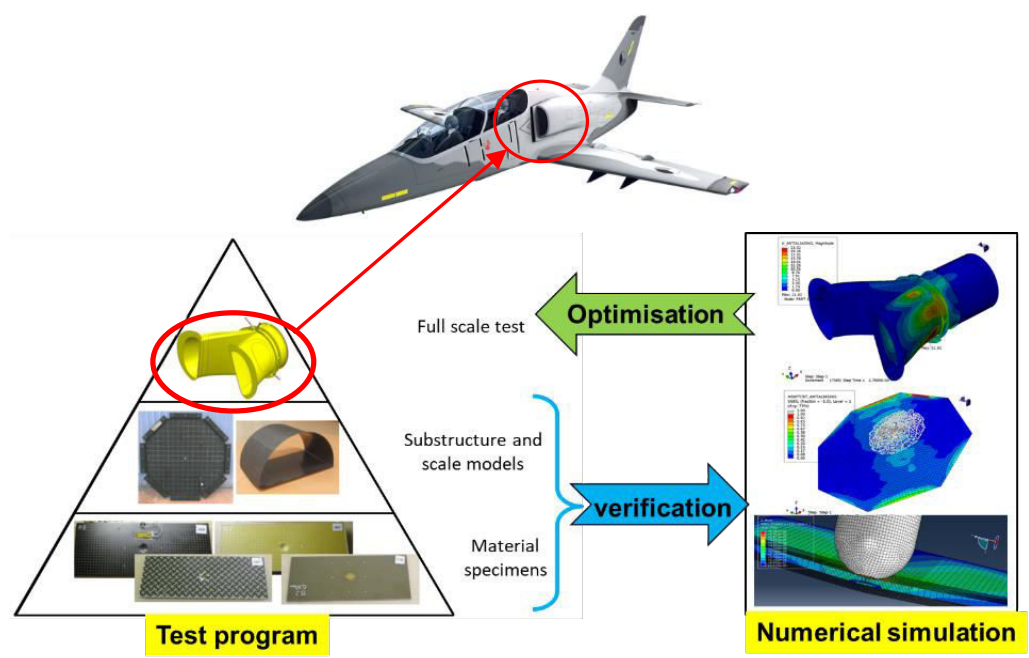

Fig. 1. Building block approach for testing and numerical simulation.

A testing programme was established to assist in the selection of a composite material and optimized lay-up from the point of view of energy absorption from bird and hail stone impacts on the air ducts of a new generation of jet training aircraft. The tests and analyses were initiated using low-impact energy tests on small test specimens [5] according to the procedures given in ASTM D7136M [6] and can be expanded to high-speed impact tests on flat test specimens to verify the manufacture and performance of a part with a complex shape. The flat test specimen used in the high-speed impact resistance verification tests was designed to provide confirmation of the performance of the selected composite material and to assist in the finite element modelling of the global structure. All numerical models were calibrated on the basis of experimental results gathered with an eye towards damage initiation and propagation behaviours. Fibre Bragg grating (FBG) sensors and strain gauge measurements were used for material calibration $[7,8]$. 


\section{Materials and methods}

\subsection{High-speed impact tests}

Physical impact tests were performed at the Czech Aerospace Research Centre (VZLÚ) based on airworthiness requirements $[9,10]$. The required impact velocity was achieved using a properly pressurized air gun-type pressure vessel. The projectiles were accelerated by compressed air through the smooth borehole of a gun barrel up to the required velocity according to specifications. Figure 2 shows the air gun test facilities.
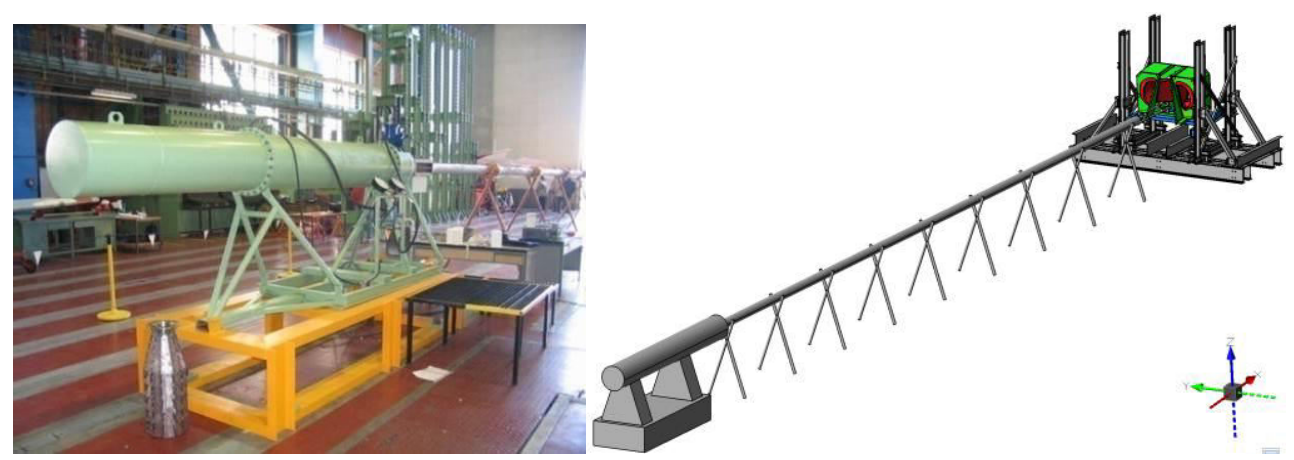

Fig. 2. VZLÚ air gun used for high-speed impact tests (left) and full-scale test arrangement (right).

\subsection{Projectiles}

The projectile used in impact tests was a $1 \mathrm{~kg}$ (nominally) bird [9], and for the hail stone simulation, ice balls with $25 \mathrm{~mm}$ and $50 \mathrm{~mm}$ diameter were used [10] (see figure 3).
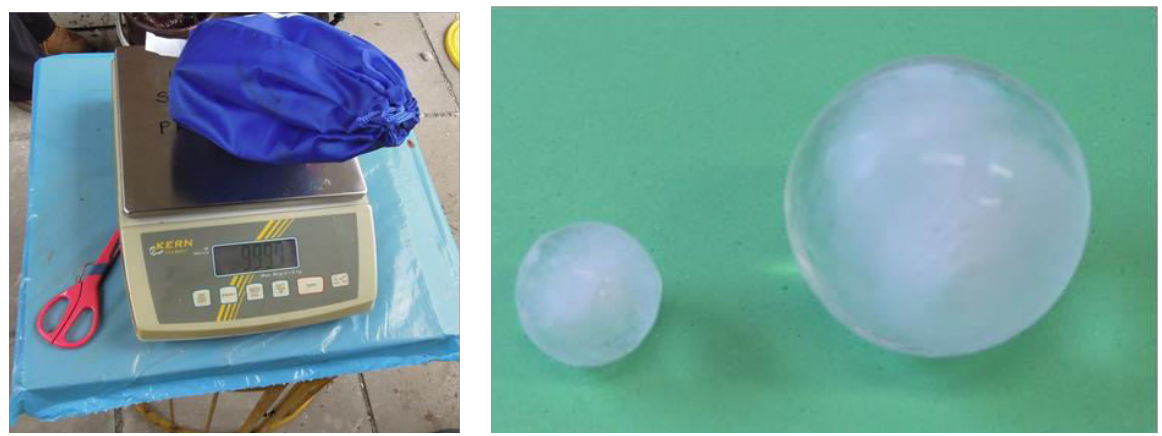

Fig. 3. Bird in a textile bag on a weighing machine (left) for bird strike tests and ice balls ( $25 \mathrm{~mm}$ and $50 \mathrm{~mm}$ ) for hail stone impact tests (right).

\subsection{Test specimen and boundary conditions}

Full-scale inlet parts were manufactured by Aero Vodochody Aerospace company using Hexply 8552/AGP193-PW prepregs [11]. The material properties of the Hexply 8552/AGP193PW-37 [11] provided in the literature [12] were used for numerical analysis and are given in Table 1. 
Table 1. Elastic material properties for Hexply 8552/AGP193PW-37 [12].

\begin{tabular}{|l|c|c|c|c|c|c|c|c|}
\hline & $\begin{array}{c}\mathrm{E} 1 \\
{[\mathrm{MPa}]}\end{array}$ & $\begin{array}{c}\mathrm{E} 2 \\
{[\mathrm{MPa}]}\end{array}$ & $\begin{array}{c}\mathrm{Nu} 12 \\
{[1]}\end{array}$ & $\begin{array}{c}\mathrm{Nu} 13 \\
{[1]}\end{array}$ & $\begin{array}{c}\mathrm{Nu} 23 \\
{[1]}\end{array}$ & $\begin{array}{c}\mathrm{G} 12 \\
{[\mathrm{MPa}]}\end{array}$ & $\begin{array}{c}\text { G13 } \\
{[\mathrm{MPa}]}\end{array}$ & $\begin{array}{c}\mathrm{G} 23 \\
{[\mathrm{MPa}]}\end{array}$ \\
\hline Hexply 8552/AGP193-PW & 60000 & 60000 & 0.046 & 0.32 & 0.32 & 5280 & 5280 & 3580 \\
\hline
\end{tabular}

E is the Young's modulus, $\mathrm{Nu}$ is Poisson's ratio, and $\mathrm{G}$ is the shear modulus.

The test stand (Figure 4) was designed and numerically verified from the viewpoint of a real boundary condition simulation (stiffness of fuselage) (see chapter 3 ).
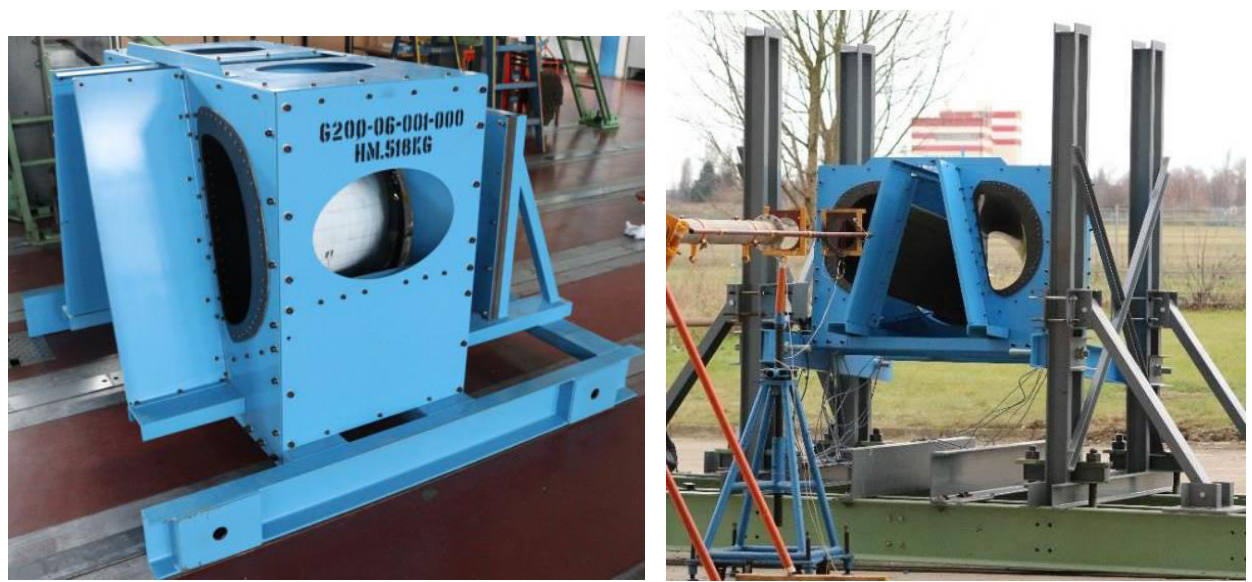

Fig. 4. Test stand (left) and impact test arrangement (right).

\subsection{Impact test procedure}

The required impact speed for the full scale test specimen was $594 \mathrm{~km} / \mathrm{h}(165 \mathrm{~m} / \mathrm{s})$ for the bird [9] and $770 \mathrm{~km} / \mathrm{h}(214 \mathrm{~m} / \mathrm{s})$ for the hail stones [10]. The real speed achieved during the tests was $629 \mathrm{~km} / \mathrm{h}$ for the bird and $789 \mathrm{~km} / \mathrm{h}$ for the hail stones. Figure 5 shows an example of high-speed camera measurement from the point of view of displacement in the impacted area and the analysis of hail stone projectile speed.
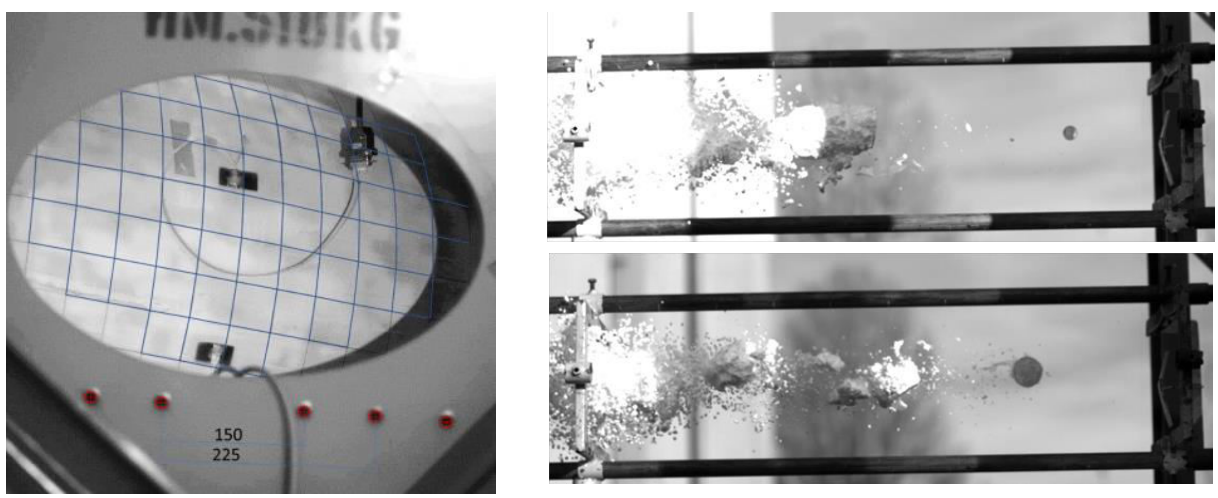

Fig. 5. High-speed camera pictures for deformation analysis in impacted area (left) and hail stone speed analysis (upper right - $25 \mathrm{~mm}$ diameter ice ball; bottom right - $50 \mathrm{~mm}$ diameter ice ball). 
The entire composite air inlet assembly was subjected to detailed non-destructive inspections before and after the impact tests. NDT (non-destructive testing) activities consisting of visual and ultrasonic inspections were performed by Level 2 qualified NDT staff [13].

During the inspections, various ultrasound technologies and methods were tested to find the most appropriate inspection procedure. Both conventional A-scan inspection using a single-element UT probe and B-scan or C-scan inspection using Phased Array technology were performed.

The following ultrasonic equipment was used for the tests:

- Flaw detector Omniscan MX2 with UT module OMNI-M-PA16128

- Single-element probe Sonatest PRDT $25505 \mathrm{MHz}$

- PA probe 5L64-A2 with contact wedge SA2-0L

- PA probe 2.25L128-I3 with contact wedge SI3-0L

- Manual PA scanner RollerFORM $5 \mathrm{MHz}$

\section{Numerical simulation}

The numerical simulation was focused from the point of view of high-energy impact on bird strike test simulations.

The bird material can be described by the so-called "elastic-plastic hydrodynamic" material model. The hydrodynamic material model is defined in ABAQUS [14] by a tabulated equation of state using Hugoniot curves for water-like homogenized bird materials $[15,16]$. The bird nodes were charged with an initial velocity, and a combination of tensile failure and shear failure criteria were used.

The geometry of the projectile (bird) was idealized as a 60 -mm-long cylinder with two hemispheric ends having a radius of $60 \mathrm{~mm}$. The bird geometry used in the simulation reflects the general geometry of the bird projectile used in the physical experiments. Figure 10 shows the geometry of the bird model, which was meshed by 10,770 C3D8R 8-node linear brick elements with conversion to particle elements (SPH - smoothed particle hydrodynamics) [14]. The density of the bird material in the model for the defined volume was established to reflect the weight of the birds used in the physical tests.

To simulate the composite structure, 4-node shell elements (S4R) with a mesh size of 10 $\mathrm{mm}$ were used. The test rig was simulated by 4-node shell elements (S4R), truss elements (T3D2) and beam elements (B31).

Figure 6 shows the finite element (FE) model of a composite air inlet with real boundary conditions (airframe - Figure 6 left) and test boundary conditions (test stand Figure 6 right).
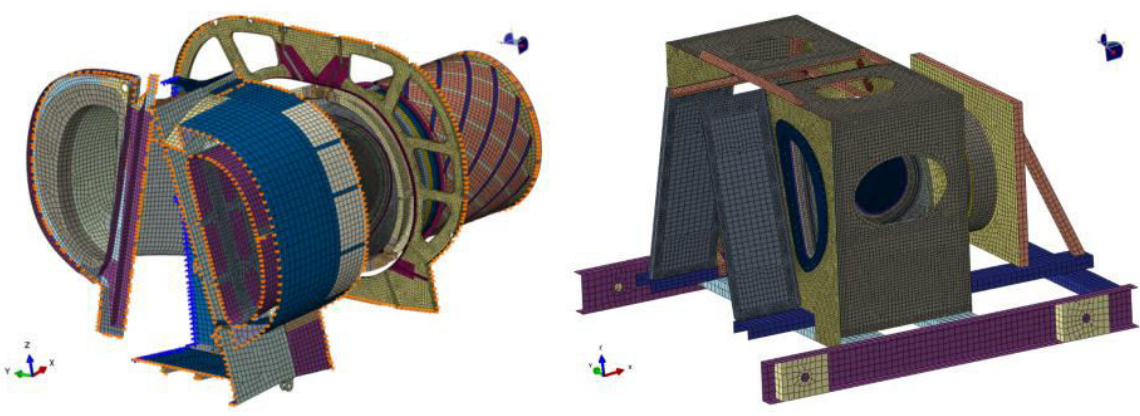
Fig. 6. FE model of air inlet in airframe (left) and test stand (right).

FE simulations were performed using the ABAQUS FE software package [14]. An explicit solver with double precision was used for the analysis. A general contact was used for contact analysis. From the point of view of damage analysis of a composite material, the Hashin tensile fibre initialization criterion was used [17].

Figure 7 shows the comparison of the damage initialization criterion contour maps between the real boundary condition (stiffness of airframe) and the test boundary condition (test stand).
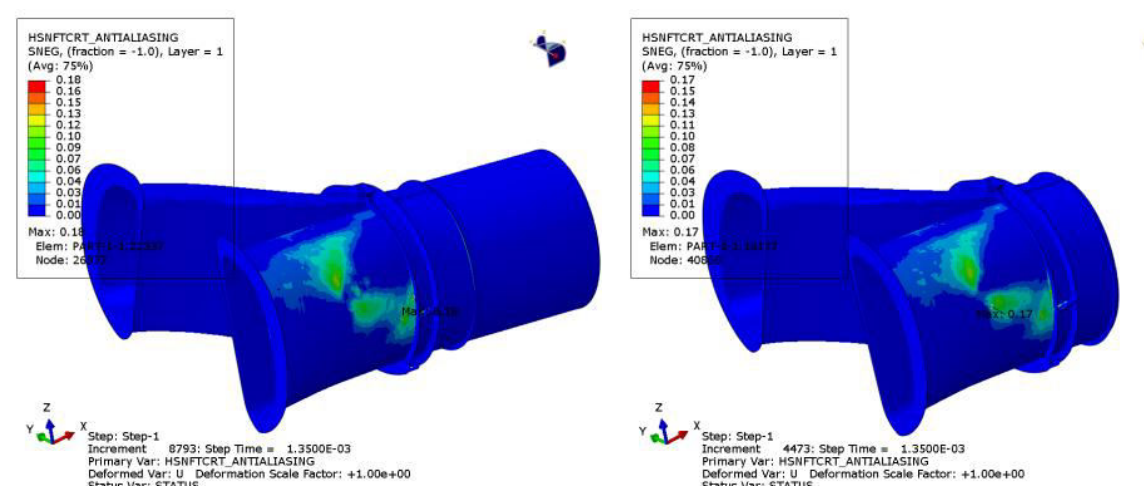

Fig. 7. Comparison of tensile fibre damage criterion contour map maximal value for the FE model with real boundary conditions (left) and the impact test simulation (right).

The numerical analysis results confirmed good impact resistance of the proposed composite air inlet without damage initialization and propagation (damage criterion $<1$ ).

\section{Comparison of results}

The results from the numerical simulation were compared with the experimental results for the bird strike test.

Figure 8 shows the results of the qualitative measurement of the maximum displacement of the composite inlet. The measurement was performed for maximal displacement, which corresponded to a $3 \mathrm{~ms}$ impact time.

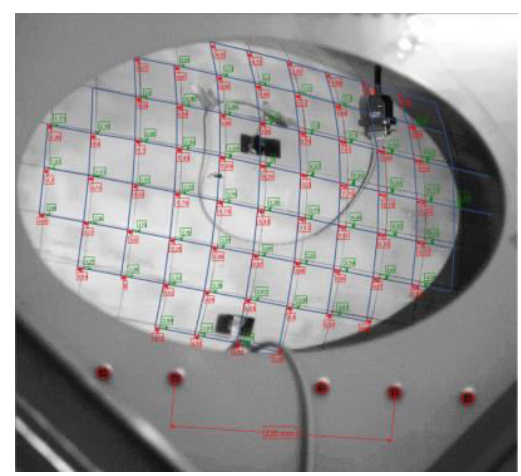

Fig. 8. Analysis of displacement on the base of grid movement from high-speed camera pictures.

Figure 9 shows displacement analyses from the FE results. 

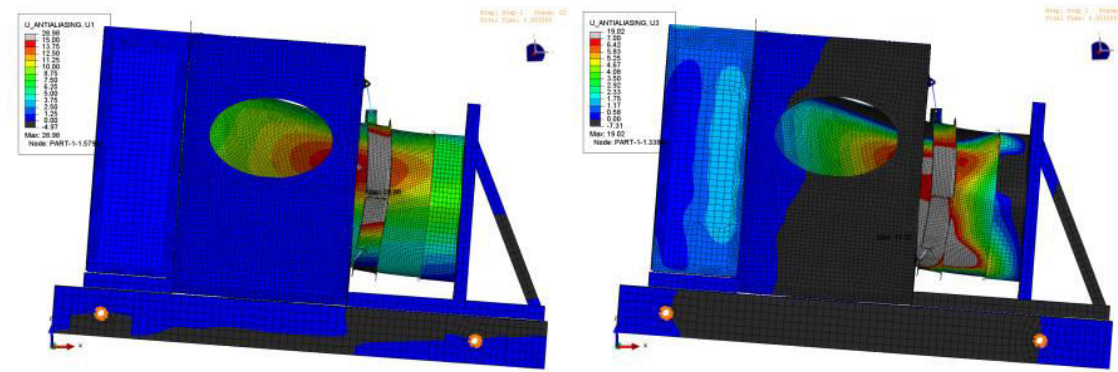

Fig. 9. Analysis of composite air inlet displacement from FEM of the bird strike test (impact time 3 $\mathrm{ms})$.

Figure 10 shows comparisons of displacement measurements from the experiment and numerical simulation.
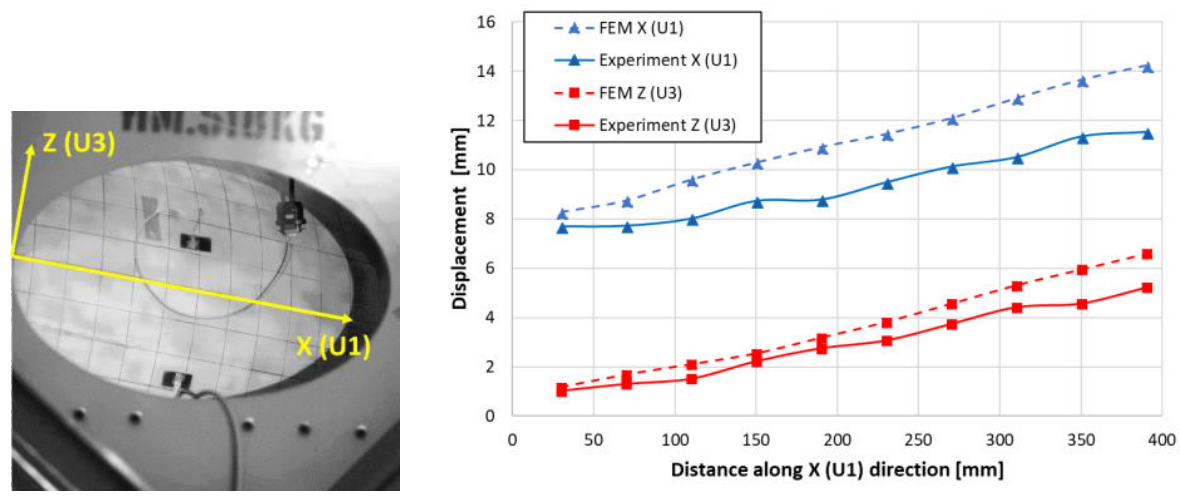

Fig. 10. Comparison between a qualitative measurement of displacement from a high-speed camera picture and the numerical simulation for a 3 ms impact time.

The difference between experiment and simulation (Figure 10) was approximately $20 \%$. The reasons for the difference include the following:

- Low resolution of pictures from the high-speed camera and distortion by perspective for qualitative measurement of displacement.

- Differences between the ideal numerical model of a bird and the real bird used for the test.

- Unknown or difficult-to-define boundary conditions (pretension of attachment rods, friction between composite parts, etc.)

A detailed inspection (NDT) after the tests did not show any defects.

\section{Conclusions}

The comparison between the test and simulation shows good agreement in the prediction of structure behaviour. The test results confirm the impact resistance of the proposed composite structure design for real service operation according to airworthiness requirements.

This work was supported by the Technology Agency of the Czech Republic (TA ČR) TE02000032 / Advanced Aerostructures Research Centre project. 


\section{References}

1. E. Cleary, R. Dolbeer, S. Wright: Wildlife Strikes to Civil Aircraft in the United States 1990-2005. Federal Aviation Administration National Wildlife Strike Database, (2005).

2. B. Yang, J, Mech. Eng. and Tech., Vol. 1 (3), pp. 92-115, (2013).

3. J. Wilbeck, Air Force Wright Aeronautical Labs, Report No. AFML-TR-77-134, Wright-Patterson AFB, OH, (1978)

4. J. Liu, Y. Li, X. Gao, Int. J. Imp. Eng., Vol. 70, pp. 21-37, http://dx.doi.org/10.1016/j.ijimpeng.2014.03006, (2014).

5. R. Batra, et al. Com. Struct., Vol. 94 (2), pp. 540-547, (2012).

6. ASTM D7136M - 07 Standard Test Method for Measuring the Damage Resistance of a Fibre-Reinforced Polymer Matrix Composite to a Drop-Weight Impact Event, (2007).

7. R. Růžek, K. Tserpes, V. Karachalios, I. Giannopoulos, V. Prentzias, Comp. Struct., Vol. 107, pp. 726-736, doi: 10.1016/j.compstruct.2013.09.053, (2014).

8. R. Růžek, M. Kadlec, K. Tserpes, E. Karachalios, Int. J. Struct. Integrity, Vol. 8 (1), pp. 134-150, https://doi.org/10.1108/IJSI-11-2015-0052, (2017).

9. ASTM F330 -10 Standard Test Method for Bird Impact Testing of Aerospace Transparent Enclosures, (2010).

10. ASTM F320-05 Standard Test Method for Hail Impact Resistance of Aerospace Transparent Enclosures, (2005)

11. HexPly® 8552 - Product Data http://www.aerospares.hu/files/hexcel/hexply_8552.pdf, March (2017).

12. S. Sánchez-Sáez, E. Barbero, C. Navarro, Comp. Science and Technology, vol. 67(11), pp. 2616-2632, https://doi.org/10.1016/j.compscitech.2006.12.002, (2007).

13. R. Růžek, R. Lohonka, J. Jironč, NDT\&E International, Vol. 39 (2), pp. 132-142, doi:10.1016/j.ndteint.2005.07.012, (2006).

14. ABAQUS 6.14 theory manual, http://abaqus.software.polimi.it/v6.14/ (2017).

15. R. Hedayati, M. Sadighi, Woodhead Publishing, ISBN: 978-0-08-100093-9, Elsevier, (2015).

16. S. Heimbs, Comp. \& Struct., Vol. 89 (23) pp. 2093-2112, (2011).

17. Z. Hashin, ASME J. App. Mech., Vol. 47, pp. 329-334, (1981). 